\title{
Avenues for the Economic Assessment of Agricultural Lands in the Development of the Agricultural Industry
}

\author{
D.A. Shapovalov*, E.V. Cherkashina and S.I. Komarov \\ State University of Land Use Planning, 15, Kazakov str., Moscow, 105064, Russia
}

\begin{abstract}
The authors consider the importance of digital technologies in the agro-industrial complex of Russia. The conclusion about the role of universities in this process has been made. Higher education institutions play a dual role. They train professional personnel having all required competencies and should be in line with all the latest innovative research projects that create a scientific and technical basis for the digital transformation of the national agriculture. The State University of Land Management has conducted research on digital land management, remote sensing tools used for the purposes of the real estate cadastre, land monitoring, and real estate assessment.
\end{abstract}

\section{Introduction}

In Russia, agricultural lands occupy $22.3 \%$ of the land fund, including arable lands, including $11.5 \%$ of hayfields, pastures, perennial plantations and fallow lands. Agricultural products produced on these lands account for $5 \%$ of the national total gross domestic product. Over the past 6 years, Russian agriculture has been the engine of economic development. In 2020, when all sectors of the economy showed a tangible decline, agriculture grew by 3-4\%, even taking into account the negative weather conditions in summer and autumn, which reduced the volume of crop yield.

Despite good economic indicators, Russian agricultural land management is characterized by negative trends accumulated over the past thirty years: a decrease in the area of agricultural lands, nonobservance of scientifically grounded alternation of crops, ignorance of land management measures, an increase in the number of land plots not involved in the economic and market turnover, erosion processes, a deterioration of the granulometric and agrochemical soil parameters.

Significant changes are occurring in the assessment of agricultural lands. In the Soviet years, the economic assessment of lands was qualitative. In particular, by determining the bonitet scores, the potential productivity of agricultural lands was determined. Currently, the economic assessment is partly incorporated into the State Cadastral Appraisal of Agricultural Land. The economic assessment is difficult due to the incomplete comparability of results, the emphasis on natural rather than cost criteria, etc.

But the need for the quality assessment is relevant. Based on the results of research within the Federal Target Program "Research and Development in Priority Areas of the Scientific and Technological Complex", the authors introduced the term "investment and resource potential" or "resource potential". It is the ability of a field, land plot, land fund of a territory to generate benefits to stakeholders using various resources (soil, spacel, climate, etc.).

\section{Materials and methods}

The qualitative assessment of the resource potential of agricultural lands can become a powerful information tool in the land management. The main difficulty in assessing the resource potential is requirements for the volume and quality of the initial information.

It is recommended to use the following parameters as an information basis for assessing the resource potential:

- soil characteristics (description of soil varieties, bonitet score, thickness of the humus horizon, content of physical clay, assimilable forms of nitrogen, mobile phosphorus, exchangeable potassium, trace elements, $\mathrm{pH}$, etc.);

- natural and climatic data (erosion, terrain slope, site shape, sum of active temperatures, precipitation, moisture content, NDVI index, soil resistance, etc.);

- information about the location (the number and quality of roads suitable for land management, remoteness from places of residence of labor resources, product sales markets, warehousing sites, transport infrastructure facilities, administrative centers, etc.);

- data on the production results of land management (gross income from the sale of agricultural products, costs of crops and livestock products, costs of soil fertility maintenance, etc.);

- information about the land market (the prevailing combination of supply and demand, price situation, level of vacancies, etc.).

\footnotetext{
Corresponding author: ShapovalovDA@guz.ru
} 
It is possible to collect, store, process and use all data only with the use of modern digital technologies.

In the agricultural production, there is a rapid development of agricultural technologies, genetic development, precision farming systems on the digital basis; the quality of fertilizers is improving, new plant protection methods are used. Information obtained can increase the production and labor productivity, optimize the supply chain and reduce operating costs. In addition to labor productivity, the improvement of technologies is aimed at reducing the volume of consumption of raw materials, the amount of waste, producing new types of products with a longer shelf life, and introducing innovative biotechnologies [1].

An increasing number of agricultural producers are integrating the Internet technologies in the crop production, in particular in the soil cultivation (unmanned aerial vehicles for monitoring crops, robotics, RFID tracking, machine learning and big data) [6]. The Russian government supports these initiatives through the project of the Ministry of Agriculture "Digital Agriculture" aimed at doubling the labor productivity by 2024 and increasing the volume of government support measures in the agro-industrial complex.

In assessment activities, similar trends are observed, the digitalization and automation of the land assessment is a pronounced trend in both developed and developing countries [3].

\section{Results}

The authors analyzed the use of digital technologies for collecting and processing initial data to assess the resource potential of agricultural lands. For these purposes, it is recommended to use the information obtained by processing space images, the results of shooting from unmanned aerial vehicles, the analysis of field survey data, etc.

Figure 1 shows an example of the results of processing multispectral satellite images with specialized software in order to obtain data on the vegetation index
(NDVI). The value of the index allows for the conclusions about the degree of development of green mass and monitoring of plant development.

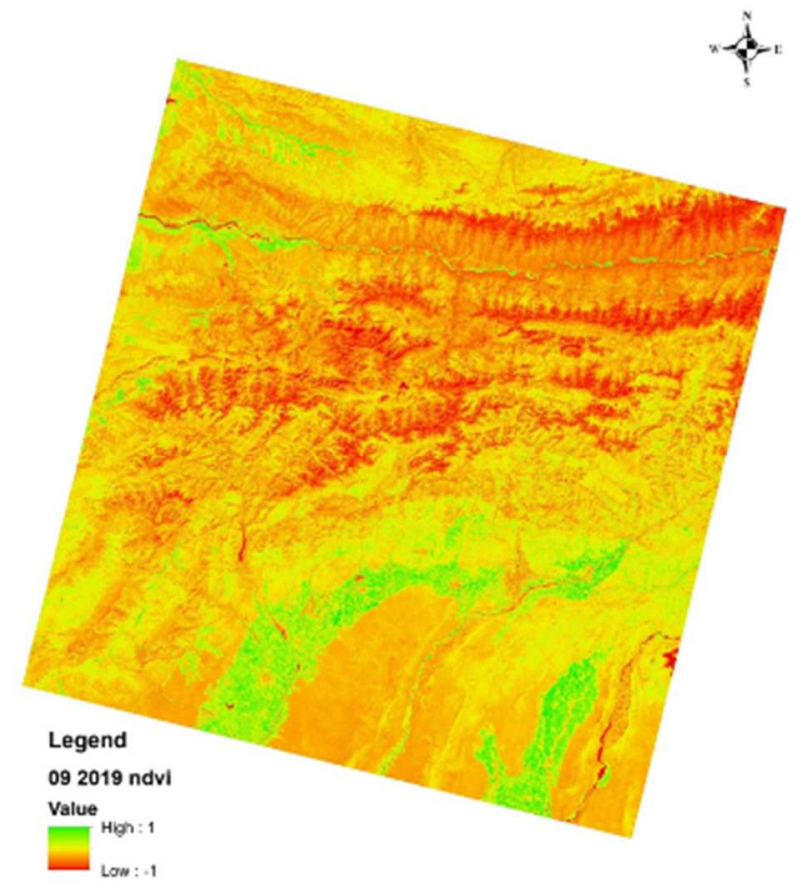

Fig. 1. The results of satellite images processing

Much attention should be paid to unmanned aerial vehicles (UAVs) used for making aerial photos of territories. By processing the results obtained, it is possible to obtain the coordinates of boundaries of land plots, fields and working plots of agricultural enterprises, to monitor the processes occurring on the lands. Figure 2 shows a drone survey, which can be used to control the operation of irrigation machines and to specify the field boundary. This information can become part of the information base for calculating the potential for the development of production forces, which is part of the resource potential.

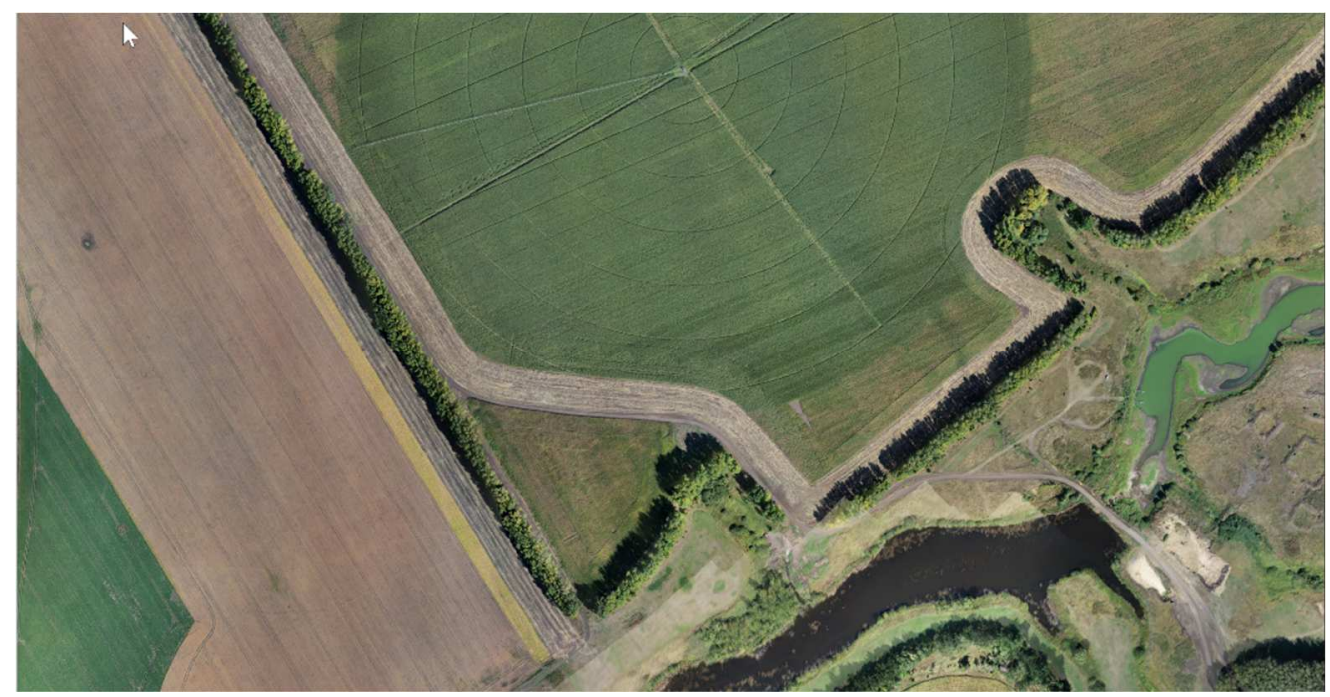

Fig. 2. Shooting of the irrigated arable land from made by an unmanned aerial vehicle 


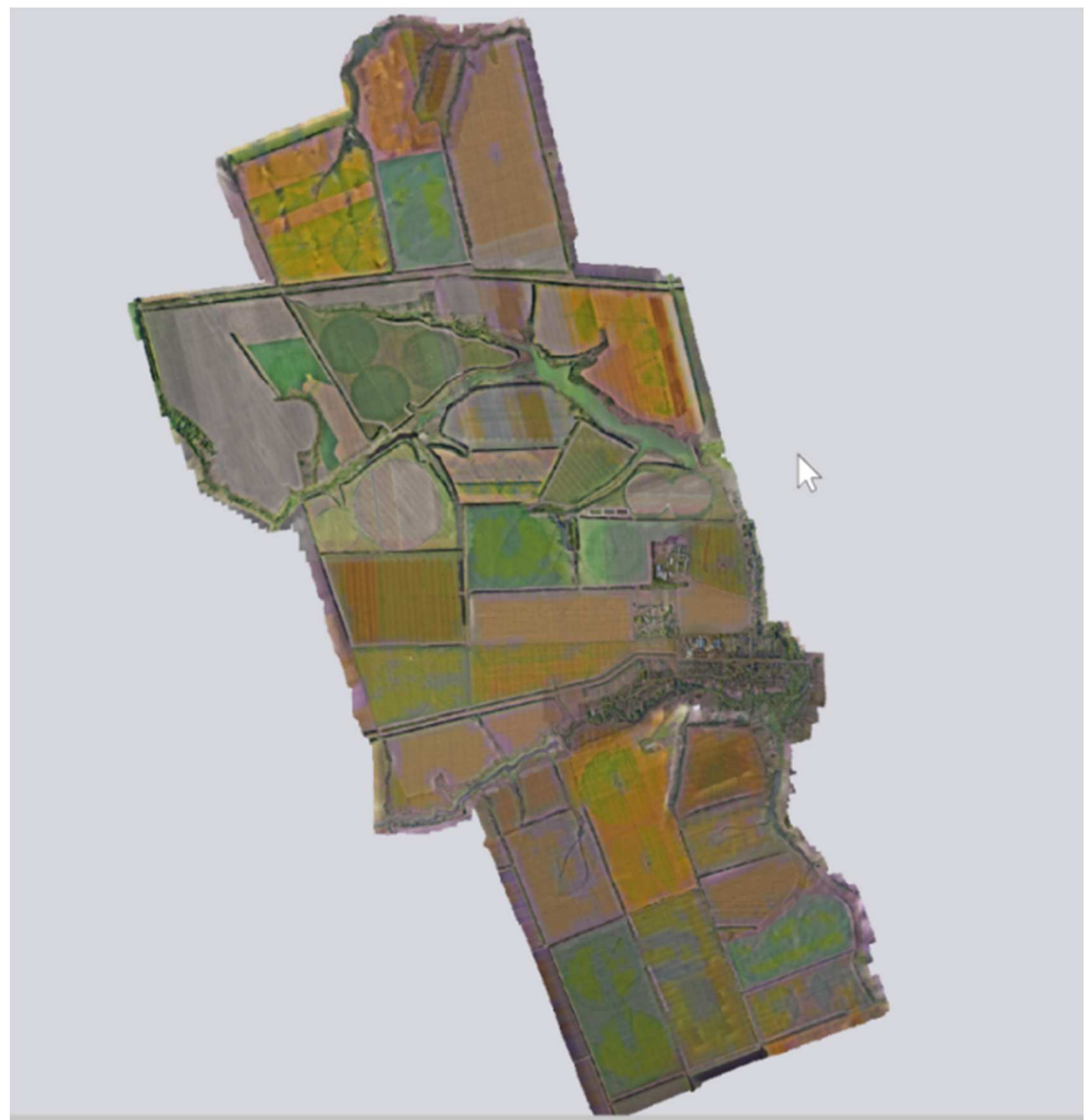

Fig. 3. The orthophoto plan of the agricultural enterprise created on the basis of shooting made by an unmanned aerial vehicle

Unmanned aerial vehicles can become the basis for calculating the resource potential of agricultural land management. In addition to the assessment process, the results can be applied in agriculture and forestry, as an emergency response, for the environmental protection, in the real estate cadastre and land management. Figure 3 shows an orthomosaic of the land use of an agricultural enterprise in Tambov region, created on the basis of a survey of the territory using the UAV, which was used to assess the resource potential of fields and work sites (Figure 4). The ranking of fields formed the basis for an on-farm land management project (Figure 5).
Works on the use of digital technologies for land management assessment are not reduced to remote sensing. The large-scale research on the automation of land management, cadastral and appraisal works is being conducted.

The digitalization of these processes can increase the number of factors affecting the quality and validity of design decisions, and decrease the cost of project development. The use of an automated land management system can bring good results both for landowners and land users, and for specialists of regional and municipal organizations which deal with spatial data [7]. 


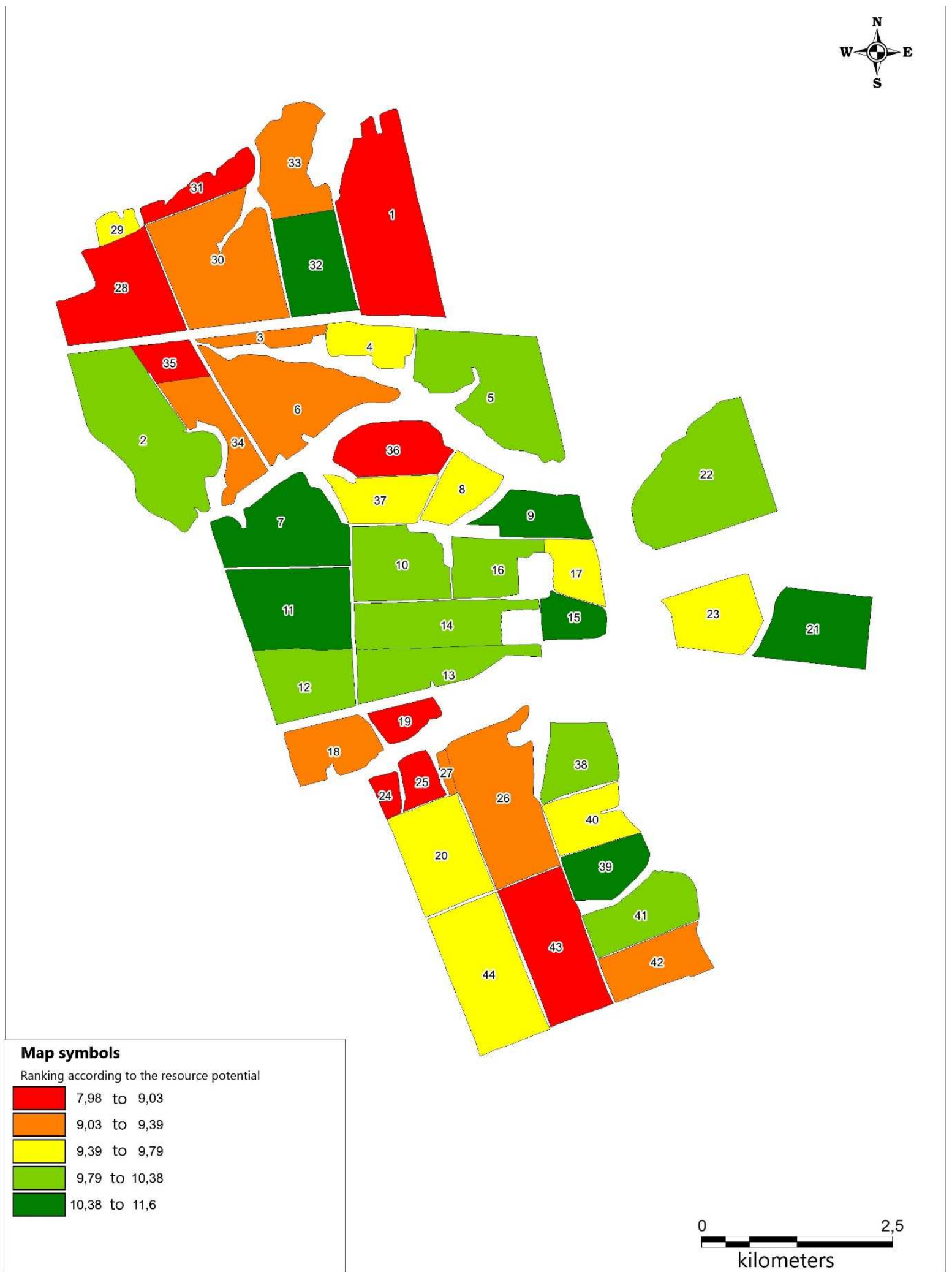

Fig. 4. Results of the assessment of the resource potential of fields and working areas of an agricultural enterprise in Tambov region 


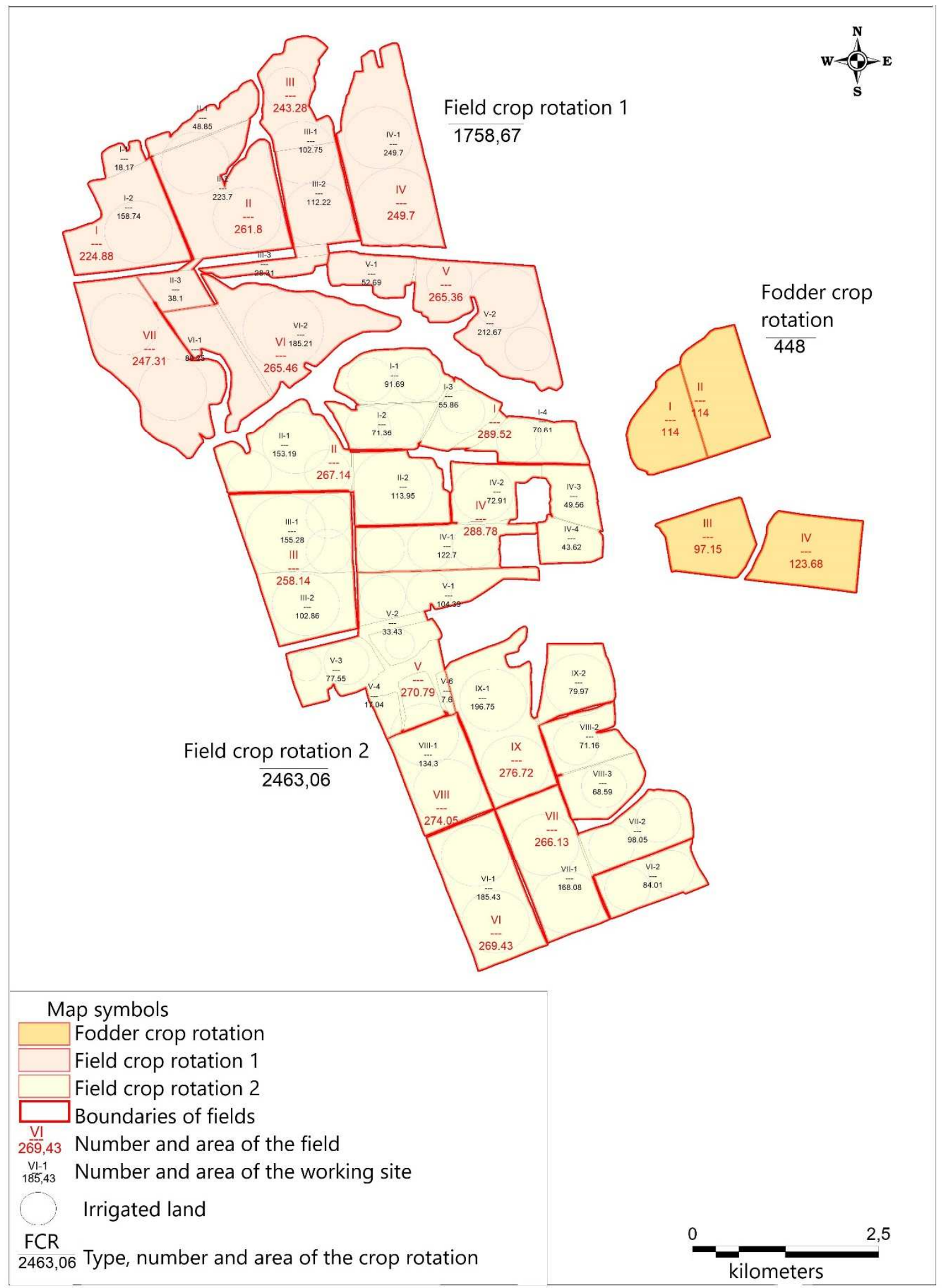

Fig. 5. The on-farm land management project for an agricultural enterprise

\section{Conclusion}

Thus, Russian agriculture is developing in the context of digitalization of the industry, use of data on climate changes, agrochemical indicators, factors of soil fertility, data on the agricultural production, etc. These data are concentrated on digital platforms that manage the agricultural enterprise. There is an opinion that there is an active gamification of agriculture, when the farmer can control and manage the process of land management using a personal computer.

At the same time, it is necessary to know in which production areas digital technologies will be useful and capable of increasing the volume of agricultural production by $60 \%$ over 10 years $[6,10]$. 
Russian land users follow the current global trends, foreign competitors have completed or are completing the transition to a new technological level.

The use of information infrastructure is limited to the use of computers and software systems for financial management and tracking commercial transactions [5]. In addition, there is a significant unevenness in the process of implementing technologies. For example, the difference between the number of farms that have digitized production processes in Krasnodar Territory and Sverdlovsk Region is more than 4 times [9].

The key obstacles to the digitalization of Russian agriculture are:

- the lack of funding for software development projects;

- the lack of databases for the use of digital technologies [2];

- the lack of highly qualified specialists capable of developing and using innovations in the production process and possessing hard and soft skills [5];

- the fragmentation of scientific research and design developments.

In these conditions, the load on the training system and research centers is increasing which must perform a double function: training of professionals in assessment activities and application of its results in agricultural production and generation of innovative scientific and technical results. Such studies can be conducted as independent projects, supported by Russian and international scientific foundations or conducted in cooperation with industrial partners $[4,8]$.

In the context of deployment of digital systems in the agro-industrial complex, there are ample opportunities for assessing the resource potential - a flexible tool that can be used at various levels. The resource potential of a particular field can be used to form a ranking of fields, to improve the information support of the land management process, to develop a system of crop rotation, to justify the location of production centers, forage lands, etc.

The resource potential of agricultural land management can be used when justifying investment projects, attracting capital investments, justifying government subsidies, etc.

The resource potential of municipalities can become a new criterion in the agrarian and industrial policy of the region, in the development of a socio-economic development sstrategy, in the distribution of budget investment resources, and for other purposes of effective management of the agricultural land management system in the region.

\section{References}

1. V.V. Buryak, V.I. Shostka, Digitalization of education: disruptive technologies in education, Human. res., 7, 21-30 (2019)

2. K. Kalashnikov, M. Zhadan, N. Baryshnikova, S. Saninsky, Digital Transformation of the AgroIndustrial Sector of Russia: Challenges and Opportunities, Proc. of the Conf. Ecological-SocioEconomic Systems: Models of Competition and Cooperation (ESES 2019) (2020), pp. 198-202, DOI: 10.2991/assehr.k.200113.040

3. S.I. Komarov, Y.S. Sinitsa, Agricultural land's valuation: Russian and foreign experience, Prop. Relat. in the Russ. Fed., 6, 42-49 (2020)

4. A.P. Kudryashova, E.V. Martynova, Pedagogical innovation in the context of educational activities, Sci. and society, 1, 85-89 (2020)

5. T. Lisienkova, O. Mukhamedzhanova, L. Komarova, Development of methodologies of innovation management for digital agricultural enterprises, E3S Web of Conf., 222, 01001 (2020), DOI: $10.1051 / \mathrm{e} 3$ sconf/202022201001

6. A.U. Mentsiev et al., IOP Conf. Ser. Earth Environ. Sci., 548, 032031 (2020)

7. T. Papaskiri, V. Semochkin, E. Ananicheva, E. Zatsepina, A. Shevchuk, Directions and methods of digital land management, IOP Conf. Ser. Earth and Environ. Sci., 579, 012130 (2020), DOI: 10.1088/1755-1315/579/1/012130

8. S.A. Rodimtsev, L.N. Ilyushina, Scientific and educational production center of the Oryol State Agrarian University, as a basis for testing innovative technologies, Bull. of Agrar. Sci., 3, 127-134 (2020)

9. A. Semin, E. Yalunina, S. Dyachkova, Digitalization of agriculture as priority direction of increase of management efficiency of the agricultural organizations, E3S Web of Conf., 176, 04015 (2020), DOI: 10.1051/e3sconf/202017604015

10. V.V. Shishkin et al., Strategic guidelines for digitalization (Publ. house VVM, St. Petersburg, 2020), 84 p. 